\title{
Facing Revolution Industrial 4.0 and Society 5.0 E- Learning be as Effective as Traditional Learning: Evidence From Indonesia
}

\author{
Diana Airawaty ${ }^{1 *}$, Wahyu Widarjo ${ }^{2}$ \\ ${ }^{1}$ Doctoral Student of PDIE Universitas Negeri Sebelas Maret, Indoenesia \\ ${ }^{2}$ Lecturer of PDIE Universitas Negeri Sebelas Maret, Indoenesia \\ *Corresponding author. Email: dianaairawaty@student.uns.ac.id
}

\begin{abstract}
This study aims to examine the effectiveness of e-learning and its impact on the education in industrial revolution 4.0 and society 5.0. It used the survey method to explore the acceptance of 125 accounting students and analyse the learning result using structural equation modelling and Mann-Whitney statistic test tools. The analysis on course delivery using two different methods did not show any significant differences in results. The same evidence was also shown by the analysis on students' acceptance of the e-learning system. This study supports the argument that an alternative teaching method using advanced technology of e-learning system can be used to improve Indonesian education in industrial revolution 4.0 and society 5.0. E-learning can solve the education problem in remote areas. This research combines Mann-Whitney test and Structural Equation modelling on TAM framework to strengthen the empirical evidence in an issue that have never been explored by other researchers.
\end{abstract}

Keywords: E-learning, traditional learning, mann-whitney, SEM, TAM.

\section{INTRODUCTION}

Technological information has developed dramatically and continuously in this decades. It has changed many aspects in the daily life without exception. Technological information can solve human problems in all walks of life since it makes everything accessible at anytime and anywhere at a convenient time. This phenomenon certainly had an impact on ways of learning and teaching too in the era of the industrial revolution 4.0 and society 5.0 as marked by digital dynamics, internet of things, artificial intelligence, biotechnology and other rapid developments in the field of technology. It certainly affects the developing countries and island countries like Indonesia with the education system that is not well-distributed and is still left behind as compared to that of the neighbouring countries and even more to that of developed countries. The low quality of Indonesian human resources results from low education quality. A study conducted by Trends International Mathematics and Science Study (TIMSS) shows that Indonesian students' performance was in the lowest level among that of the other countries [1]. The same result was also shown by the PISA OECD reports [2].

The Indonesian government through The Ministry of Research and Technology has issued regulation to permit e-learning system as one of the learning methods with certain criteria. Yet, this policy has not widely been used in Indonesian education even though the government has stipulated this regulation for years [3]. Many Indonesian academicians supported e-learning, but many of whom still believed that traditional method is better than e-learning system even though some previous researches in the developed countries have proved the effectiveness of e-learning such as [4], [5], and [6]. Therefore, this study aims to prove the effectiveness of e-learning as compared to the traditional systems. Observation was done not only to examine the effectiveness but also to explore the students' acceptance of e-learning system. It is expected that the government can refer to this study the study can be to improve the future learning methods and to evaluate and develop education delivery methods, especially for the developing country that needs to enhance its education level in the revolution industry 4.0 and society 5.0 .

\section{LITERATURE REVIEW}

There are many studies related to e-learning methods. These studies proved that students with elearning method had an excellent understanding level of the materials [7]. Likewise, similar result was also demonstrated by [8] who explored medical students studying with distance learning based on traditional systems combined with e-learning methods. It was revealed that students were interested in learning 
materials that were presented in the online form because the platform made them easier to access the materials at anytime and anywhere as illustrated by [9] and [10]. However, despite the advantages, e-learning or distance learning also have the weaknesses. Therefore, many academicians still persist on using traditional method that facilitate instructors and students visually [7]. Based on observations of other researchers on e-learning methods, it was found that the presence of instructors was very important [11]. On this basis, we found a research gap in the previous studies revealing inconsistent results. In addition, those researches were mostly conducted in developed countries, and only a few of which were conducted in developing countries. Meanwhile, most of Indonesians live in rural areas with poor education method.

\section{Technology Acceptance Model}

Technology Acceptance Model (TAM) was proposed by Davis in 1989. The purpose of TAM is to provide a decisive explanation for computer acceptance and to provide an explanation of user behavior, who are mostly an end user of a computer technology and user population. TAM not only predicts but also explains things so researchers and practitioners can understand why someone rejects or accepts a particular system [12]. Another researcher of TAM, [13] also proved its' reliability in examining the acceptance of information.

\section{RESEARCH MODEL AND HYPOTHESIS}

\section{Research Model}

The first statistic test was held to examine whether evaluation scores taken from the two different group were different or not.

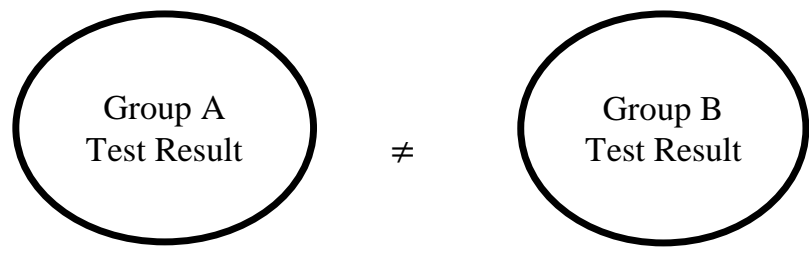

Fig. 1. Research Model 1

The second observation was conducted on group C, Business Ethics courses students who had an e-learning class in the semester observed.

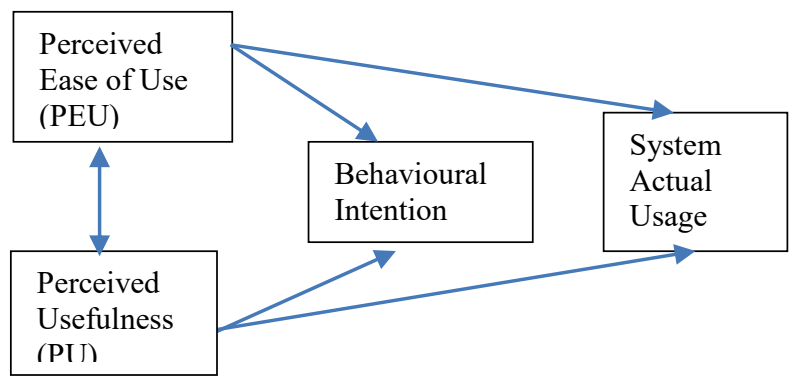

Fig. 2. Research Model 2

\section{Research Hypothesis}

Based on the research objective and question, we propose the following research hypothesis:

Research hypothesis for Model 1:

H1: Group A test result is the same with group B test results.

Research Hypothesis for Model 2:

$\mathrm{H} 1$ : PEU is intercorrelated with PU in e-learning.

$\mathrm{H} 2$ : PU has a positive effect on BI in e-learning.

$\mathrm{H} 3$ : PEU has a positive effect on BI in e-learning.

$\mathrm{H} 4$ : PU has a positive effect on AU in e-learning.

H5: PEU has a positive effect on AU in e-learning.

$\mathrm{H} 7$ : BI has a positive effect on $\mathrm{AU}$ in e-learning.

\section{METHOD}

The observation was conducted without prior notice to the students who were being evaluated. The observation was done on the Business Ethic classes, which took place in year 2019. The first observed students were professionals who were working while studying. Due to differences in number of students in the two observed classes, we used Mann-Whitney test to seek for empirical evidence.

Yogyakarta is a famous student city in Indonesia. Many students from many other islands in Indonesia come to study to the city. Mercu Buana Yogyakarta is a one of private universities in Yogyakarta, which have many students from all over other cities and islands in Indonesia. These numerous students represent the entire population in Indonesia since they have various demographic background. Hence, the study observed three groups of students in this university. Two groups were evaluated from the students' test results and analysed with the Mann-Whitney statistical test. Meanwhile, the third group was observed from their acceptance of e-learning system.

The first two group were part time students with professional background, who studied at Mercu Buana University, Yogyakarta while working. After attending a course for one semester, the students observed were tested for their acceptance of the courses delivered using a modified TAM framework due to the use of mandatory e-learning. The questionnaire was distributed to students then the data from the questionnaire were tested using SEM Amos.

Class A contained 17 of students who were treated with traditional face-to-face course delivery methods. Meanwhile, class B had 34 students who were treated by e-learning method. The third group was all student that took Business Ethics course in one semester. The test conducted after the business ethics course was taught during the observation period. This research was designed to determine learning outcomes with e- 
learning systems and the acceptance of students for the e-learning system.

\section{RESULT AND DISCUSSION \\ Data Analysis and Result}

Asymp Value of Sig. (2-tailed) is 0.527 higher than 0.05 . This shows that there is no difference in the average value between classes A and B. Meanwhile, the result of SEM analysis empirically proves that PEU has a significant positive effect to $\mathrm{BI}$.

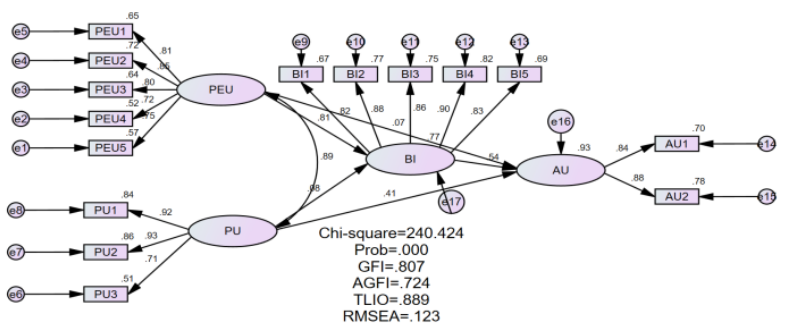

Fig. 3. The Result of Structural Equation Model

\section{Discussion}

The observation to group A and B shows that the Mann-Whitney statistic test for both groups empirically are the same. This evidence is in line with the previous research which states that the educational outcomes provided by distance learning facilities are as good as face to face method. The telemedicine course can succeed as an on-site course in ATLS training [4]. It is in line with the research conducted by the medical faculty [14] which found that sending lectures to deal with traumatic patients with e-learning was as effective as the face-to-face method in the classroom.

There have been many studies to compare the elearning and traditional learning method and the results demonstrates that e-learning system is an effective method. The research on cartography students also show the similar results that studies with e-learning and traditional methods are the same [15]. On the other hand, the SEM test on group C (Figure 1) strengthens the result of the Mann-Whitney test. SEM output shows the empiric evidence that PEU and PU have a significantly positive effect to BI while BI has a positive and significant effect on AU. Unfortunately, this study cannot prove the positive effect of PU to BI. The strength of this result demonstrates that PEU is the main reason for the user to use the e-learning system.

\section{CONCLUSION AND LIMITATION}

This study provides empirical evidence that there is no difference in academic results between e-learning and traditional learning methods or face-to-face classroom learning method. The delivered material is more important than the way it was delivered. Moreover, in this industrial revolution iera, young people or millennials are familiar with technological advancement. Certainly, this research enriches the fact that e-learning can be implemented by formal education to improve the Indonesian education. Industrial revolution 4.0 and society 5.0 are golden ways to facilitate and improve education and to develop the education for the entire population, especially for those who live in the remote areas in Indonesia with limited road access.

E-learning method is not only beneficial for people in the rural areas, but also for those who have limited time to study such as students who work while studying. All type of student can enhance their ability and make themselves to become more knowledgeable and keep with the updates to enhance their level of education despite their restricted condition. A noteworthy point is that the system must provide the students with ease of use to promote the intention to use the system.

However, this research has some limitations. First, this study disregards the characteristics of lecturers and students as the objects of observation. Learning methods, content and an in-depth delivery of the material and case illustrations by senior and junior lecturers may differ, which can influence the perception and achievement of student's learning process. Students' characteristics or types can also affect the learning outcomes. Students of independent learner type will be easier to understand the material presented by lecturers both using traditional methods and elearning method. Therefore, further studies need to consider the characteristics of lecturers and students as the research samples. Secondly, future studies must add other variables to strengthen empirical evidence.

\section{REFERENCES}

[1] Parker, L. \& Prabawa-Sear. Environmental Education in Indonesia Creating Responsible Citizens in Global South. Education in Indonesia. Chapter 5. pp. 84-85. Routledge. 2020.

[2] PISA 2015 Result (Volume I): Excellence \& Equity in Indonesia. Online retrieved from https://www.oecd-ilibrary.org/.

[3] Saragih et al. Student Perception of Student Centres e-Learning Environment (SCeLE) as Media to Support Teaching. IOP Conference Series: Earth and Environmental Science. 2019.

[4] Ali et al. Telemedicine as a potential medium for teaching the advanced trauma life support (ATLS) course. Journal of Surgical Education. 2013.

[5] Estriegana et al. Student Acceptance of Virtual Laboratory and Practical Work: An Extension of The Technology Acceptance Model. Computer and Education. 2019. 
[6] Law et al. Student Enrolment, Motivation and Learning Performance in A Blended Learning Environment: The Mediating Effects of Social, Teaching, and Cognitive Presence. Computer and Education. 2019.

[7] Shantakumari, N. \& Sajith, P. Blended Learning: The Student Viewpoint. Annals of Medical and Health Sciences Research. 2015.

[8] Shimizu et al. Does Blended Problem-Based Learning Make Asian Medical Student Active Learners: A Prospective Comparative Study. BMC Medical Education (2019).

[9] Pham et al. Does e-Learning Service Quality Influence e-Learning Student Satisfaction and Loyalty? Evidence from Vietnam (2019).

[10] Suresh et al. Effect of e-Learning on Academic Performance of Undergraduate Students. Drug Invention Today.2018.

[11] Law et al. Student enrolment, motivation and learning performance in a blended learning environment: The mediating effects of social, teaching, and cognitive presence. Computers and Education (2019).

[12] Davis, D, Fred. Perceived Usefulness, Perceived Ease of User Acceptance of Information Technology. MIS Quarterly. September (1989).

[13] Lu, C \& Ting, C. A. Study of Tax e-Filing Acceptance Model: A Structural equation Modelling Approach. Proceeding Conference on Computer and Information Science, ICIS (2013).

[14] Farakhmand et al. Distance Learning Can Be as Effective as Traditional Learning for Medical Students in The Initial Assessment of Trauma Patients.

[15] Ware L, Jared. Evaluating Online and Traditional Learning Environments Using Cartographic Generalization Techniques. Cartographical 53:2, pp.107-114. University of Toronto Press (2018). 